\title{
Introduction to research at the policy frontier in Latin America
}

\author{
Sebastian Galiani ${ }^{1}$
}

Published online: 10 November 2015

(C) The Author(s) 2015. This article is published with open access at Springerlink.com

This special issue was made possible, thanks to funding from the Office of Strategic Planning and Development Effectiveness (SPD) of the Inter-American Development Bank (IDB). The issue was conceived by Sebastian Martinez (SPD) and by Sebastian Galiani, of the University of Maryland, who wrote the introduction and contributed to several of the articles. The coordinators acknowledge the support of Carola Alvarez (IDB) and Arturo Galindo (SPD) in the preparation of the papers, and they thank Paloma Acevedo (SPD) for overseeing the editing and production process.

Over the past 10 years, the IDB has supported efforts by the research and policy community to undertake rigorous evaluations of programs and policies throughout the region. The purpose of the articles included in this issue is to take stock of certain areas-health, education, housing and infrastructure, and climate changeand propose the next frontier of research to support enactment of more effective policies going forward that take into account the region's economic and social priorities. Needless to say, the topics covered in this issue are not exhaustive, and work is already under way on a new set of topics-including poverty, crime, pensions, and labor markets - that we expect to publish in 2017.

In the first article of this issue, Maria Victoria Anauati, Sebastian Galiani, and Federico Weinschelbaum define a health policy frontier, which is understood as the primary interventions according to the current health priorities of Latin America. The paper analyzes the region's ongoing epidemiological and demographic transitions and addresses the challenges faced by policymakers. Over the past two

Sebastian Galiani

galiani@econ.umd.edu

1 Department of Economics, University of Maryland and NBER, 3105 Tydings Hall,

College Park, MD 20742, USA 
centuries, Latin America has experienced both a secular decline in mortality and a significant improvement in health. Today the region is well advanced in its demographic and epidemiological transition: Latin American countries have undergone profound demographic changes, which are variously reflected in the decrease in population growth and in population ageing. Furthermore, health problems are now highly concentrated on noncommunicable diseases (NCDs), and there is little doubt that their levels will substantially increase in the near future.

Taking into account the stages where the region is in terms of its transitions, the health policy frontier must include (1) public health policies that reduce risk factors that cause NCDs by promoting healthy behaviors; and (2) health insurance programs that offer households effective access to quality health care at reasonable costs. Since these two issues are the region's main health policy priorities, much of this paper is devoted to analyzing how public health interventions can encourage changes toward healthier behaviors, and how policymakers can expand access to health insurance programs in a context of high labor informality.

In terms of behavior, interventions that create environments conducive to making healthy choices might not be effective if there are biases that lead individuals to take suboptimal decisions - a phenomenon that should not be ignored by policymakers. The authors explore this issue by developing a theoretical model of household decision-making that assesses how lack of knowledge and self-control problems affect individual behavior related to food consumption, which later leads to weight problems and obesity. Behavior plays an important role in several NCDs, although each disease should be analyzed separately. The theoretical model provides a crucial conclusion: knowledge gaps affect the rational choice of individuals. Robust evidence on policy interventions that address these biases is rather limited. Looking across the spectrum of health behaviors the authors show that programs involving counseling together with behavioral interventions seem to be the most effective in improving weight-related behaviors or outcomes.

In terms of access and insurance, policymakers must deal with the paradox of trying to expand access to health care in a context of high labor informality. Since health insurance in Latin America is mostly provided within the labor market, effective access to health care services is restricted to workers in the formal sector. This excludes informal sector workers who make up approximately 50 percent of the region's labor force. Following Galiani and Weinschelbaum (2012), the authors present a theoretical framework that assesses the relationship between health insurance and the labor market finding that workers with low levels of human capital generally work in the informal sector, and that an expansion of health insurance coverage will increase the size of the formal sector as well as the wages of informal sector workers.

Given the current stage of Latin America's demographic and epidemiologic transition and the significant share of NCDs in the region's morbidity and mortality patterns, the suggested areas for future research are (1) how to expand and make health care accessible and affordable for individuals in a context of high labor informality, and (2) how to develop effective interventions that influence individuals toward healthy behaviors in the face of time inconsistency and knowledge constraints. 
In the second article, Miguel Urquiola describes the current situation of educational quantity and quality in Latin America and looks at priorities for research. The paper shows that in terms of quantity-defined as how much contact individuals have with the school system-educational systems in Latin America are not underperformers. Moreover, in absolute terms, measures of educational quantity have been improving over time. Nevertheless, four challenges remain: (1) expanding preprimary enrollment; (2) reducing delayed entry among 6- and 7-year-olds; (3) raising rural enrollment in the 8-13-year-old age range; and (4) reducing dropout rates in the 14-17-year-old age range.

In contrast, educational quality-defined as the skills individuals gain from contact with school system-is low in the region. This is reflected in terms of absolute performance on national and regional tests, as well as relative performance on international tests_-even adjusting for per capita income. As a result, this paper is focused on the quality of Latin American education.

The author reviews the progress economists have made toward devising evidence-based educational policy, and highlights several remaining challenges in the region. In keeping with this article, the discussion at times emphasizes Latin America, although the evidence comes from, and the conclusions are meant to apply to, countries in other regions and with diverse income levels.

The first challenge involves expanding research on the casual effects of school inputs. Making progress in this area requires dealing with three main obstacles: (1) data availability, as there are few available standardized measures of skill; (2) methodological issues that involve ascertaining the causal effects of each input; and (3) availability of cost information, that is, data that render cost-effectiveness comparisons feasible.

The second challenge involves producing a full-scale road map for an evidencebased education policy. Specifically, the focus of this work has been on generating a ranking of inputs and interventions in terms of cost-effectiveness, with the rationale that such ranking will one day guide policy throughout the developing world.

There has been less work on the effects of educational inputs during the preschool stage. Therefore, further work on the impact of preschool inputs represents a third challenge. In contrast, there has been progress on understanding the effects of incentives within education. For example, there is significant work on the effects of introducing competition in school systems. However, in general, the effects of voucher and analogous initiatives have not been nearly as robust or positive as most economists expected. As a result, further progress is needed in understanding how to improve the design of policies introducing competition.

Finally, the author argues that there is relatively less work surrounding the effects of inputs provided by parents and students, both in terms of resources and effort. The key issue here is to what extent parental and student effort matter, and how their level of effort responds to incentives. For example, returns to skills in the labor market, or in admission to universities, may be crucial in determining the attitudes of parents and students toward skill accumulation. Furthermore, understanding these incentives may be essential not only to school system design but also to correctly exploiting all the knowledge gained from experimentation. 
In the third article, Laura Jaitman identifies the main problems in housing and transport infrastructure in Latin America and the Caribbean and examines the effect of past interventions aimed at improving the living standards of the urban poor.

In recent decades, the global urbanization trend has been driven by the developing world. Latin America, however, is an outlier among the developing regions because of its strikingly high urbanization rate. And as cities in the region were not prepared for such rapid and unplanned urbanization, the expected benefits of urbanization did not materialize for many migrants, resulting in the "urbanization of poverty."

Regarding access to formal housing, Latin American ownership rates are higher on average than in other developing regions, although large disparities remain between countries and income groups. The rental sector for low-income residents in the region is undeveloped, and most slum dwellers do not have secure property rights. Regarding transport systems, overall mobility—as measured by the number of daily trips per person-ranks low in the region in comparison with countries in the Organization for Economic Cooperation and Development. A salient pattern is the exponential growth of motorization in the region. Latin America does not rank high in road infrastructure, which exacerbates the problems of pollution and congestion brought about by excessive motorization. Another problem with motororiented transportation in the region is that not everyone can afford to buy a car. Thus, the poor rely basically on mass public transit, which has low coverage and, although subsidized, is very expensive for those with low incomes.

Improving access to formal housing and upgrading mass public transit are the two main priorities to prevent the formation of new slum areas and attenuate the growth of existing irregular settlements. In relation to the first priority of access to formal housing, the authors find that there are supply constraints, such as scant availability of units for the low-income population segment, and demand constraints such as insufficient income to afford private sector dwellings and the inability to document income. In relation to the second priority related to mass public transit, the author notes that while incentive-based measures such as congestion pricing are successful in reducing congestion and pollution in the developed world, there are technological barriers to the implementation of such systems in Latin America.

Improving the quality of life in informal settlements is another policy priority. Since the 1980s, "in situ" slum upgrading has become popular based on the notion that it is both socially and economically more desirable. However, it seems that integral slum upgrading programs are necessary to produce more profound and long-lasting changes to improve the living standards of the urban poor.

The first suggested area for future research is on ways to make mass public transit accessible and affordable for the poor, and on how this can in turn affect consumption of housing services and shape a city's spatial patterns. Policies that integrate transport reforms with the supply of housing for low-income households seem the most promising to prevent the formation of new slum areas. In terms of access to formal housing, there is scant knowledge on the best way to expand the housing supply for the poor or promote the rental market for low-income households, which to date has been neglected. As for land titling to formalize the poor, there are still some important open research questions. Finally, for existing 
slums, rigorous evaluation of integral slum upgrading programs would be useful to determine the most effective and efficient way to undertake such initiatives.

Finally, in the last article of this issue, Brian Feld and Sebastian Galiani describe projected trends in climate change for Latin America and the consequence these changes could have in the region. Research and policy on climate change in the region are still in the early stages, hence this article is mostly devoted to providing some insight into which steps should be taken first, where research efforts should be directed, and how policy measures should be evaluated before being carried out.

The authors develop a theoretical framework that draws partly on previous literature and reach three main conclusions for the region. First, the financing for mitigation-defined as the reduction of greenhouse gas emissions-depends mostly on foreign transfers. Mitigation is a global public good, thus its benefits are not fully internalized by the country that bears its cost. In turn, the benefits of mitigation expenditure are related to whether it can significantly reduce the stock of emissions. It is expected that this effect will be marginal in environmentally small economies relative to the emissions generated by large economies (Chisari et al. 2013). Second, public spending on adaptation-which refers to all measures taken to increase resilience and reduce damage produced by climate change-will be positive even for environmentally small economies. Unlike mitigation, adaptation does not always entail an international positive externality, so countries that engage in this type of policies can secure their benefits for themselves. Third, investment in public goods that are useful even in the absence of climate change will be positive irrespective of the size of the economy.

Although these conclusions allow inferring the type of strategies worth considering under different contexts, the question of which policies Latin American countries should pursue to address climate change is still unclear. To elucidate this, the authors describe the steps that should be followed, and note the importance of policymakers carrying out cost-benefit analysis of policies under consideration to determine which ones are worth implementing. Based on both cost-benefit considerations and the theoretical framework, the article argues that Latin America should focus mainly in adaptation to cope with climate change consequences, and in carrying out traditional development policies that will increase resilience but will also be welfare-improving in the absence of climate change.

Notwithstanding that there is still little evidence on how climate change will affect economic systems and which sectors should be given priority when considering adaptation policies, the article argues that the agricultural and livestock sector, in particular, might well be an area of priority.

Finally, the article deals with the question of what to do if the proper international incentives are put in place to encourage mitigation in environmentally small economies such as those in Latin America. Recent research points to the comparative advantage Latin America might have in conserving and managing its vast forest areas so that the region can act as a huge carbon sink (Chisari and Galiani 2010).

Open Access This article is distributed under the terms of the Creative Commons Attribution 4.0 International License (http://creativecommons.org/licenses/by/4.0/), which permits unrestricted use, 
distribution, and reproduction in any medium, provided you give appropriate credit to the original author(s) and the source, provide a link to the Creative Commons license, and indicate if changes were made.

\section{References}

Chisari O, Galiani S (2010) Climate change: a research agenda for Latin America and the Caribbean. In: IDB technical note 164. Inter-American Development Bank, Washington, DC

Chisari O, Galiani S, Miller S (2013) Optimal climate change adaptation and mitigation in environmentally small economies. In: IDB working paper no. 417. Inter-American Development Bank, Washington, DC

Galiani S, Weinschelbaum F (2012) Modeling informality formally: households and firms. Econ Inq 50(3):821-838 